\title{
Lack of Associations between TNF- $\alpha$ Polymorphisms and Cervical Cancer in Thai women
}

\author{
Teeraporn Chinchai ${ }^{1}$, Krittaphak Homchan ${ }^{2}$, Watanyoo Sopipong ${ }^{2}$, Jira \\ Chansaenroj $^{2}$, Sukumarn Swangvaree ${ }^{3}$, Pairoj Junyangdikul ${ }^{4}$, Sompong \\ Vongpunsawad $^{2}$, Yong Poovorawan ${ }^{2 *}$
}

\begin{abstract}
The risk of developing cervical cancer in women infected with human papillomavirus (HPV) may be influenced by an individual's genetic susceptibility. Published data linking single nucleotide polymorphisms (SNPs) in the tumor necrosis factor-alpha (TNF- $\alpha$ ) promoter region at positions -308G $>A$ (rs1800629) and -238G $>$ A (rs361525) to cervical cancer risk have been inconclusive. In this study, we examined 251 cervical specimens and classified them into two groups according to their cytological findings: 121 cancer cases and 130 controls (low-grade squamous intraepithelial lesion and normal cytology). All specimens were typed by PCR and sequencing for TNF- $\alpha$ promoter -308G >A (rs1800629) and -238G $>$ A (rs361525). The genotype distribution of SNPs in either rs1800629 or rs361525 did not significantly demonstrate higher frequency in the cancer group ( $\mathrm{p}=0.621$ and $\mathrm{p}=0.68$, respectively). Based on these results, neither the TNF- $\alpha$ promoter $-308 G>A(r s 1800629)$ nor the $-238 G>A$ (rs361525) polymorphism presents a major risk factor for cervical cancer among Thai women. Larger studies are necessary to elucidate possible genetic mechanisms influencing cervical cancer development.
\end{abstract}

Keywords: Human papillomavirus - TNF- $\alpha$ - sequencing - single nucleotide polymorphism - cervical cancer risk

Asian Pac J Cancer Prev, 17 (3), 953-956

\section{Introduction}

Cervical cancer is the fourth most common cancer in women worldwide and represents $7.5 \%$ of all female cancer deaths. In 2012, it is estimated that there were 528,000 new cases of cervical cancer and 266,000 deaths worldwide. In developing countries, limited access to screening, vaccination, and effective treatment contributes to relatively high morbidity and mortality. The agestandardized incidence rate of cervical cancer in Thailand is approximately 17.8/100000 person-year (Ferlay et al., 2015). Infection with the human papillomavirus (HPV) is attributed to the development of nearly all cervical cancer (Snijders et al., 1999; Bosch et al., 2002; Bosch and de Sanjose., 2003; Chin'ombe et al., 2014; Ermel et al., 2014). In addition, hormonal, nutritional and environmental factors as well as host genetic susceptibility such as single nucleotide polymorphisms (SNPs) further contribute to the risk of cancer development (Kohaar et al., 2007).

Genetic polymorphisms in several important genes have been examined for correlation between specific allele variants and cancer progression (Chansaenroj et al., 2013). These genes encode cytokines, which mediate the immune response and have been implicated in the development of cancer (Dranoff, 2004). Tumor necrosis factor-alpha (TNF- $\alpha$ ) is a potential pro-inflammatory cytokine, which plays a critical role in a wide range of inflammatory, autoimmune, and malignant diseases (Bazzoni and Beutler., 1996; Beutler and Bazzoni., 1998). TNF mediates carcinogenesis by inducing proliferation, invasion, and metastasis of tumor cells (Shishodia et al., 2003). SNPs have been identified in the promoter region of TNF- $\alpha$ and potentially affect the regulation of TNF- $\alpha$ transcription. TNF- $\alpha$ gene lies in the major histocompatibility complex class III region on the short arm of chromosome 6 (6p21.3) (Hajeer and Hutchinson, 2000). One of the two most common polymorphisms in the promoter region of TNF- $\alpha, \mathrm{G}$ to A substitution at position -308 , resulted in higher level of TNF- $\alpha$ production than the $-308 \mathrm{G}$ allele (Kroeger et al., 1997). Additionally, there is a putative repressor site located in a 25-bp stretch including the position -238, resulting in $\mathrm{G}$ to A substitution at position -238 in the TNF- $\alpha$ promoter, which might also affect TNF- $\alpha$ expression (Fong et al., 1994).

Case-control studies have been performed to examine the association between $\mathrm{TNF}-\alpha$ promoter region $-308 \mathrm{G}>\mathrm{A}$ and $-238 \mathrm{G}>\mathrm{A}$ polymorphisms with cancer susceptibility, 
including breast, lung, nasopharyngeal, and cervical cancer (Deshpande et al., 2005; Shih et al., 2006; Pooja et al., 2011; Sousa et al., 2011). The available data linking these SNPs and cervical cancer, however, have been inconclusive or contradictory. The aim of this study is to compare the polymorphisms of the TNF- $\alpha$ promoter region $(-308 \mathrm{G}>\mathrm{A}$ and $-238 \mathrm{G}>\mathrm{A})$ in $\mathrm{HPV}$-infected Thai women with normal or low-grade squamous intraepithelial lesion (LSIL) versus cancerous cytology in order to determine possible association between the risk of developing cervical cancer and these polymorphisms.

\section{Materials and Methods}

\section{Study population}

One hundred and twenty-one patients from the National Cancer Institute in Thailand with cancerous cervical cytology were included in this study. In addition, the control group comprised 130 patients with normal or LSIL cytology from Bangpakok 9 International Hospital and Samitivej Srinakarin Hospital in Bangkok (Table 1). Cervical cells were sampled and all patients had HPV infection. This study was approved by the Institutional Review Board (IRB number 071/56) of the Faculty of Medicine, Chulalongkorn University. Informed consent was obtained from all participants.

\section{Polymorphism analysis}

Germline DNA was extracted from cervical cells by the standard phenol/chloroform extraction method. The TNF- $\alpha-308 \mathrm{G}>\mathrm{A}$ and $-238 \mathrm{G}>\mathrm{A}$ genotypes were determined by PCR and sequencing. Briefly, polymerase chain reaction (PCR) amplifications were performed with the master mix (5 PRIME Inc., Hamburg, Germany), DNA template $(25-100 \mathrm{ng})$ and $0.2 \mu \mathrm{M}$ solution of the specific primers including SNP_F8092: 5'-GAAGGAAAC AGA CCA CAG AC-3' and SNP_R8521: 5'-TTG CTT CTC

Table 1. Demographic Data of All Cervical Samples in this Study

\begin{tabular}{lcc}
\hline & Control & Cancer \\
\hline No. & 130 & 121 \\
Age & & \\
Range & $19-88$ & $35-81$ \\
Average & 39.9 & 51.7 \\
SD & 12.3 & 10.5 \\
Cytology normal & 36 & \\
LSIL & 94 & \\
CA & & 121 \\
\hline
\end{tabular}

TCC CTC TTA GC-3'. The final volume was made up to $25 \mu 1$ with sterile water. The reaction conditions were $95^{\circ} \mathrm{C}$ for $5 \mathrm{~min}, 40$ cycles at $95^{\circ} \mathrm{C}$ for $30 \mathrm{~s}, 55^{\circ} \mathrm{C}$ for $30 \mathrm{sec}$ and $72^{\circ} \mathrm{C}$ for $45 \mathrm{~s}$, followed by a final extension of $7 \mathrm{~min}$ at $72^{\circ} \mathrm{C}$. All PCR products were separated by electrophoresis on a $2 \%$ agarose gel stained with ethidium bromide, and visualized with ultraviolet light. The PCR products were purified using the gel extract kit (GeneAll, Seoul, Korea) according to the manufacturer's instructions and were sequenced (First BASE Laboratories, Selangor, Malaysia).

\section{Statistical analysis}

Allele and genotype frequencies of the TNF- $\alpha$ $-308 \mathrm{G}>\mathrm{A}$ and $-238 \mathrm{G}>\mathrm{A}$ positions were analyzed manually based on the chromatogram of nucleotide bases using Chromas Lite (v.2.01) and compared to the reference sequence retrieved from GenBank database (http:// www.ncbi.nlm.nih.gov/). Odds ratios (ORs) with 95\% confidence intervals $(95 \% \mathrm{CI})$ were used to evaluate the strength of the associations between the TNF- $\alpha-308 \mathrm{G}>\mathrm{A}$ and $-238 \mathrm{G}>\mathrm{A}$ polymorphisms and two groups of cervical cytology. Statistical analyses were performed by Microsoft Excel using $\chi^{2}$ contingency table analysis. A P-value $<0.05$ was considered statistically significant.

\section{Results}

All samples in this study were HPV-DNA positive by PCR and sequencing. Although there were roughly equal numbers of individuals in the control and the cancer group, the age distribution for the cancer group was narrower (35-81 years) (Table 1). Mean age of the cancer group and the control group are 51.7 and 39.9 years, respectively. Among the 130 cervical samples in the control group, there were twice as many samples with LSIL cytology than with normal cytology.

Genotyping of the rs1800629 showed that most individuals in both groups possessed the GG alleles (Table 2). The frequency of either heterozygous or homozygous AA was also similar between the two groups. These differences were not statistically significant $(\mathrm{P}=0.621)$. Similarly, the majority of the individuals in both groups possessed genotype GG at the locus rs361525 ( $\mathrm{P}=0.68)$. There were no individuals with the AA alleles.

\section{Discussion}

Cervical cancer is a common gynecological cancer among women especially in developing countries.

Table 2. Genotype Frequencies of TNF- $\alpha$ Promoter Gene Polymorphism in Cancer and Control Groups

\begin{tabular}{|c|c|c|c|c|c|}
\hline SNP & Genotype & $\begin{array}{c}\text { Cancer } \\
(\mathrm{N}=121)\end{array}$ & $\begin{array}{l}\text { Control } \\
(\mathrm{N}=130)\end{array}$ & OR $(95 \% \mathrm{CI})$ & $P$-value \\
\hline $\begin{array}{l}\text { TNF- } \alpha-308 \\
(\text { rs1800629) }\end{array}$ & $\begin{array}{l}\text { GG } \\
\text { GA } \\
\text { AA }\end{array}$ & $\begin{array}{c}108(89.3 \%) \\
11(9.1 \%) \\
2(1.7 \%)\end{array}$ & $\begin{array}{c}113(86.9 \%) \\
15(11.5 \%) \\
2(1.5 \%)\end{array}$ & $1.19(0.59-2.40)$ & 0.621 \\
\hline $\begin{array}{l}\text { TNF- } \alpha-238 \\
(\mathrm{rs} 361525)\end{array}$ & $\begin{array}{l}\text { GG } \\
\text { GA } \\
\text { AA }\end{array}$ & $\begin{array}{c}114(94.2 \%) \\
7(5.8 \%) \\
0\end{array}$ & $\begin{array}{c}124(95.4 \%) \\
6(4.6 \%) \\
0\end{array}$ & $0.80(0.27-2.40)$ & 0.68 \\
\hline
\end{tabular}


Although HPV infection is responsible for the oncogenic transformation, disease development also depends in part on the infected individual's genetic factor. In recent years, the associations between genetic polymorphisms and cancer susceptibility have been extensively investigated, and there is evidence to suggest that certain alleles located in the proximity of key regulatory genes could contribute to individual differences in cancer susceptibility.

Inflammation enables precancerous and early cancerous lesions of the cervix, leading consequently to cervical cancer (Luthra et al., 1987; Bornstein et al., 1995). Tumor necrosis factor-alpha (TNF- $\alpha$ ) is a proinflammatory cytokine secreted by activated macrophages (Kroeger et al.,1997; Dranoff, 2004) and plays a pivotal role in human immune response to a number of pathogens, such as HPV. Several studies revealed that TNF- $\alpha$ is a versatile cytokine with multiple functions, including defending cells against viral infections and at times serving as a cancer promoter. (Brinkman et al., 1995; Kroeger et al., 2000; Eksteen et al., 2001)

Previous studies have shown that TNF- $\alpha$ may be linked to the development of HPV-associated cervical cancer. Elevated levels of a number of cytokines including $\mathrm{TNF}-\alpha$ were increased in the cervicovaginal washings of patients with cervical cancer (Tjiong et al., 2001). Levels of TGF- $\beta$ and TNF- $\alpha$ mRNA in HPV-positive cells were increased compared to the nontumorigenic control cells (Bequet-Romero and Lo' pez-Ocejo, 2000). Chronic inflammation and the release of proinflammatory cytokines such as IL- $1 \alpha$ and TNF- $\alpha$ might provide a selective growth advantage for abnormal cervical cells in vivo (Woodworth et al., 1995).

In our study, comparison of the genotype frequencies between the HPV-positive cancer and the control group did not reveal statistically significant association for either rs 1800629 or rs361525. It is possible that this study was limited by the sample size whereby minor genetic effects may be masked. Age-matching between cancer and control groups may also be needed, but this presents a challenge because advanced cancerous progressions are usually found in the older individuals compared to those with normal or early stage abnormal cytology. HPV genotypes may also play a role in combination with the polymorphism. Although all samples were HPVpositive, specific HPV genotypes were not identified in these samples. It is known that high risk and low risk HPV genotypes gave the different in cervical cancer pathogenesis.

Previous study demonstrated that the less common

$\mathrm{TN} \alpha$ (-308A) allele (Wilson et al., 1992) is strongly associated with the MHC haplotype HLA-A1, B8, DR3 which is associated with high TNF production (Wilson et al., 1993). In our study, rs1800629 genotype AA was found in both groups of patients, albeit in very few individuals. The most common HLA types among Thais are HLA-A2, B46 and DR9. Moreover, association of these 2 SNPs with risk of cervical cancer using meta-analysis suggested that TNF- $\alpha$-238A allele significantly decreased cervical cancer risk and the TNF- $\alpha-308 \mathrm{G}>\mathrm{A}$ polymorphism is associated with the susceptibility to cervical cancer in Caucasian and
African population (Pan et al., 2012). For common HLA alleles and Asian population, polymorphism in TNF- $\alpha$ promoter gene is not a risk factor for cervical cancer in the Thai population.

In conclusion, based on the results of the present study, neither the TNF- $\alpha-308 \mathrm{G}>\mathrm{A}$ nor the TNF- $\alpha-238$ $\mathrm{G}>\mathrm{A}$ polymorphism is a major risk factor among Thai women with cervical cancer. The further studies on the correlation between host and viral factors are necessary to reveal potential diagnostic and therapeutic benefits from such association.

\section{Acknowledgements}

This study was supported by Research Grant from the Faculty of Medicine, Srinakharinwirot University (044/2556), the National Research University Project, Office of Higher Education Commission (WCU-58-006HR), The Research Chair Grant from the National Science and Technology Development Agency, Chulalongkorn University Centenary Academic Development Project (CU56-HR01), Center of Excellence in Clinical Virology, Ratchadaphiseksomphot Endowment Fund of Chulalongkorn University (RES560530093), The Outstanding Professor of Thailand Research Fund (DPG5480002), Siam Cement Group, and MK Restaurant Company Limited. We would like to express our gratitude to the entire staff of the Center of Excellence in Clinical Virology, Faculty of Medicine, Chulalongkorn University, who have made this study possible. We also thank the staff of the Department of Pathology, National Cancer Institute, Samitivej Srinakharin and Bangpakok 9 International Hospital, Thailand for providing the samples.

\section{References}

Bazzoni F, Beutler B (1996). The tumor necrosis factor ligand and receptor families. $N$ Engl J Med, 334, 1717-25.

Bequet-Romero M, Lopez-Ocejo O (2000). Angiogenesis Modulators Expression in Culture Cell Lines Positives for HPV-16 Oncoproteins. Biochem Biophys Res Commun, 277, 55-61.

Beutler B, Bazzoni F (1998). TNF, apoptosis and autoimmunity: a common thread? Blood Cells Mol Dis, 24, 216-30.

Bornstein J, Rahat MA, Abramovici H (1995). Etiology of cervical cancer: current concepts. Obstet Gynecol Surv, 50, 146-54.

Bosch FX, de Sanjose S (2003) Chapter 1: human papillomavirus and cervical cancer-burden and assessment of causality. $J$ Natl Cancer Inst Monogr, 31, 3-13.

Bosch FX, Lorincz A, Munoz N, et al (2002). The causal relation between human papillomavirus and cervical cancer. J Clin Pathol, 55, 244-65.

Brinkman BM, Zuijdeest D, Kaijzel EL, et al (1995). Relavance of the tumor necrosis factor alpha (TNF alpha)-308 promoter polymorphism in TNF alpha gene regulation. J Inflamm, 46, 32-41.

Chansaenroj J, Theamboonlers A, Junyangdikul P, et al (2013). Polymorphisms in TP53 (rs1042522), p16 (rs11515 and rs3088440) and NQO1 (rs1800566) genes in Thai cervical cancer patients with HPV16 infection. Asian Pac J Cancer Prev, 14, 341-6.

Chin'ombe N, Sebata NL, Ruhanya V, et al (2014). Human 


\section{Teeraporn Chinchai et al}

papillomavirus genotypes in cervical cancer and vaccination challenges in Zimbabwe. Infect Agent Cancer, 9, 16.

Deshpande A, Nolan JP, White PS, et al (2005). TNF-alpha promoter polymorphisms and susceptibility to human papillomavirus 16-associated cervical cancer. J Infect Dis, 191, 969-76.

Dranoff G (2004). Cytokines in cancer pathogenesis and cancer therapy. Nat Rev Cancer, 4, 11-22.

Eksteen JA, Scott PA, Perry I, et al (2001). Inflammation promotes Barrett's metaplasia and cancer : a unique role for TNF-alpha. Eur J Cancer Prev, 10, 163-6.

Ermel A, Ramogola-Masire D, Zetola N, et al (2014). Invasive cervical cancers from women living in the United States or Botswana: differences in human papillomavirus type distribution. Infect Agent Cancer, 9, 22.

Ferlay J, Soerjomataram I, Dikshit R, et al (2015). Cancer incidence and mortality worldwide: sources, methods and major patterns in GLOBOCAN 2012. Int J Cancer, 136, 359-86.

Fong CL, Siddiqui AH, Mark DF, et al (1994). Identification and characterization of a novel repressor site in the human tumor necrosis factor alpha gene. Nucleic Acids Res, 22, 1108-14.

Hajeer AH, Hutchinson IV (2000). TNF-alpha gene polymorphism: clinical and biological implications. Microsc Res Tech, 50, 216-28.

Kohaar I, Thakur N, Salhan S, et al (2007). TNFalpha-308G/A polymorphism as a risk factor for HPV associated cervical cancer in Indian population. Cell Oncol, 29, 249-56.

Kroeger KM, Carville KS, Abraham LJ (1997). The-308 tumor necrosis factor-alpha promoter polymorphism effects transcription. Mol Immunol, 34, 391-9.

Kroeger KM, Steer JH, Joyce DA, et al (2000). Effects of stimulus and cell type on the expression of the -308 tumour necrosis factor promoter polymorphism. Cytokine, 12, 110-9.

Luthra UK, Prabhakar AK, Seth P, et al (1987). Natural history of precancerous and early cancerous lesions of the uterine cervix. Acta Cytol, 31, 226-34.

Pan F, Tian J, Ji CS, et al (2012). Association of TNF- $\alpha-308$ and-238 polymorphisms with risk of cervical cancer : a meta-analysis. Asian Pac J Cancer Prev, 13, 5777-83.

Pooja S, Francis A, Bid HK, et al (2011). Role of ethnic variations in TNF- $\alpha$ and TNF- $\beta$ polymorphisms and risk of breast cancer in India. Breast Cancer Res Treat, 126, 739-47.

Shih CM, Lee YL, Chiou HL, et al (2006). Association of TNFalpha polymorphism with susceptibility to and severity of non-small cell lung cancer. Lung Cancer, 52, 15-20.

Shishodia S, Majumdar S, Banerjee S, et al (2003). Ursolic acid inhibits nuclear factor- kappa B activation induced by carcinogenic agents through suppression of IkappaBalpha kinase and p65 phosphorylation: correlation with downregulation of cyclooxygenase 2 , matrix metalloproteinase 9, and cyclin D1. Cancer Res, 63, 4375-83.

Snijders PJ,Peto J, Meijer CJ, et al (1999). Human papillomavirus is a necessary cause of invasive cervical cancer worldwide. J Pathol, 189, 12-9.

Sousa H, Breda E, Santos AM, et al (2011). Genetic risk markers for nasopharyngeal carcinoma in Portugal: tumor necrosis factor alpha -308G >A polymorphism. DNA Cell Biol, 30, 99-103.

Tjiong MY, van der Vange N, ter Schegget JS, et al (2001). Cytokines in cervicovaginal washing fluid from patients with cervical neoplasia. Cytokine, 14, 357-60.

Wilson AG, de Vries N, Pociot F, et al (1993). An allelic polymorphism within the human tumor necrosis factor $\alpha$ promoter region is strongly associated with HLA-A1, B8, DR3 alleles. J Exp Med, 177, 557-60.

Wilson AG, di Giovine FS, Blakemore AI, et al (1992). Single base polymorphism in the human tumour necrosis factor alpha (TNF- $\alpha$ ) gene detectable by Ncol restriction of PCR product. Hum Mol Genet, 1, 353.

Woodworth CD, Mumullin E, Iglesias M, et al (1995). Interleukin la and tumor necrosis factor a stimulate autocrine amphiregulin expression and proliferation of human papillomavirus-immortalized and carcinoma-derived cervical epithelial cells. Proc Natl Acad Sci, 92, 2840-44. 